\title{
Effect of tillage and crop on arbuscular mycorrhiza colonization of winter wheat and triticale under Mediterranean conditions
}

\author{
I. Brito ${ }^{1}$, M. J. Goss ${ }^{2} \&$ M. de Carvalho ${ }^{1}$ \\ ${ }^{1}$ Universidade de Évora, ICAAM, Apartado 94, 7002-554 Évora, Portugal, and ${ }^{2}$ Kemptville Campus, University of Guelph, \\ Kemptville, ON KOG 1J0, Canada
}

\begin{abstract}
Large-scale inoculation with arbuscular mycorrhizal fungi (AMF) is generally impractical in most regions and we have little understanding of the factors that determine inoculation success. Nevertheless, the ability to take full advantage of indigenous AMF for sustainable production needs to be developed within cropping systems. We used part of a long-term field experiment to understand the influence of tillage and the preceding crop on AMF colonization over the growing season. Arbuscular mycorrhiza colonization rate was more affected by treatment (tillage or the combination of crop and preceding crop) than by the total number of AMF spores in the soil. Conventional tillage (CT) had a statistically significant negative effect $(P \leq 0.05)$ on spore numbers isolated from the soil, but only in the first year of study. However, the AMF colonization rate was significantly reduced by CT, and the roots of wheat, Triticum aestivum, L, cv. Coa after sunflower, Helianthus annuus L., were less well colonized than were those of triticale, X Triticosecale Wittmack, cv. Alter after wheat, but the affect of tillage was more pronounced than was the effect of crop combination. Under no-till there was a significant increase in AMF colonization rate throughout the sampling period in both wheat and triticale, indicating that the extraradical mycelium previously produced acted as a source of inoculum. In general, triticale showed greater AMF colonization than wheat, despite the preceding crop being less mycotrophic. Under these experimental conditions, typical of Mediterranean agricultural systems, AMF colonization responded more strongly to tillage practices than to the combination of crop and preceding crop.
\end{abstract}

Keywords: Arbuscular mycorrhiza, tillage, crop rotation, wheat, triticale, sunflower

\section{Introduction}

Arbuscular mycorrhizal fungi (AMF) are an important component of the soil biota in most agroecosystems. The obligate symbiosis they form with the majority of crop plants (95\% of the present-day species of plants belong to families that are mycorrhizal) (Smith \& Read, 1997) can range from mutually beneficial to parasitic depending on the soil, crop and endophyte conditions (Johnson et al., 1997; Graham \& Abbott, 2000; Al-Karaki et al., 2004). In general, many benefits accrue to plants from their association with AMF (Gupta et al., 2000), even if at times these benefits are not obvious or easily quantifiable. The importance of mycorrhiza is greater under marginal biotic or abiotic conditions, as they can confer

Correspondence: I. Brito. E-mail: ibrito@uevora.pt

Received September 2011; accepted after revision March 2012 important, or even decisive, comparative advantages to their host, acting like a kind of 'life insurance'. This may be particularly important in the agronomic context of the Mediterranean regions, taking into consideration the great variability of the climate and the marginal soils under cropping.

Given that large-scale inoculation with AMF is generally impractical in most regions and we have little understanding about the consequences of using inocula (Schwartz et al., 2006), the development of management practices that maximize the benefits of this naturally occurring symbiosis is important. Tillage and crop rotation are key agronomic practices that need to be considered in developing sustainable production systems.

The cultivation of crops that are their natural hosts can increase the population of AMF while maintaining mycorrhizal activity in soil (Vestberg et al., 2005). As a result, spore densities in the soil tend to build up (Black \& Tinker, 
1977; Karasawa et al., 2000) leading to improved colonization of the succeeding crop, which may only take place in the following season (Gavito \& Miller, 1998; Miller, 2000; Troeh \& Loynachan, 2003). Arihara \& Karasawa (2000) studied the effects of preceding crop on AMF colonization of maize. They found that shoot weight and grain yield of maize were significantly larger following sunflower, maize, soybean or potato compared with nonmycorrhizal canola, sugar beet or an uncropped 'fallow'.

Tillage system influences the physical, chemical and biological environment of the soil, but their consequences for crop performance depend also on multiple interactions involving the soil, the climate and the crop itself. Therefore, the effect of different tillage systems, particularly the two most contrasting ones [no-till (NT) and conventional tillage (CT)] on the crop performance can be favourable to the first (Triplett \& Van Doren, 1969) or to the latter (Martin-Rueda et al., 2007). For AMF, the direct effects of the various tillage practices, particularly CT and NT systems, are related to physical disruption of the hyphal network and to the mixing of surface residues within the soil profile. These can negatively impact the effectiveness of AMF (Kabir, 2005), particularly the timing of colonization (Goss \& de Varennes, 2002). The number of spores, length of extraradical mycelium and hyphal density, particularly in the row zone, can be enhanced when soil disturbance is reduced (Kabir et al., 1998a). This leads to generally greater AMF colonization of plants cultivated under NT than CT (Evans \& Miller,1988; Kabir et al., 1998b), unless a very large density of AMF inoculum is available (McGonigle \& Miller, 2000).

When host plants are present and the soil is not disturbed, runner hyphae (Friese \& Allen, 1991) from colonized roots and soil mycelium network are the main source of mycorrhizal inoculum (Klironomos \& Hart, 2002). They are more rapid and efficient in initiating colonization than spores (Read et al., 1976; Martins \& Read, 1997), which can be considered as 'long-term' propagules (Kabir, 2005). An important factor is the longer time that spores take to germinate and make contact with roots compared with runner hyphae. As extraradical mycelium can survive throughout the Mediterranean summer (Brito et al., 2011) when the soil is not disturbed (Jasper et al., 1989), deep ploughing (to more than $15 \mathrm{~cm}$ ) hinders subsequent mycorrhiza formation by disrupting the extraradical mycelium developed in the previous season, and by reducing propagules density in the rooting zone (Abbott \& Robson, 1991; Kabir et al., 1998b).

To manage AMF colonization within the cropping system, we investigated the importance of the crop and preceding crop on the abundance of arbuscular mycorrhiza (AM) inoculum and root colonization of wheat and triticale in the context of a long-term tillage experiment under field conditions. We hypothesized that the tillage system, by modifying the proportion of the different types of inoculum, will be more important than the effect of the crop or the preceding crop in the rotation in the establishment of new mycorrhizas.

\section{Materials and methods}

The study was conducted at the Revilheira research station, Alentejo $\left(38^{\circ} 28^{\prime} \mathrm{N} 7^{\circ} 28^{\prime} \mathrm{W}\right)$, Portugal. It was located on an experiment, which was started in 1995 to investigate longterm effects of soil tillage and measurements made over two consecutive cropping seasons (1998-2000), when the tillage treatments had been in place for 3 yrs. Two tillage systems were compared: CT, which involved annual mouldboard ploughing to a depth of $20 \mathrm{~cm}$ followed by disk harrowing to create a seedbed, and NT, in which seeds were drilled into undisturbed soil. These treatments were arranged in a complete randomized block design with three replicates. The crop rotation was wheat (Triticum aestivum, L, cv. Coa) triticale (X Triticosecale Wittmack, cv. Alter) - sunflower (Helianthus annuus L.). The main experiment required three adjacent fields to have all the elements of the rotation present in each year. Two fields (one in each year) were used in this study. During the 1997-1998 season, wheat was not sown due to excessive rainfall at seeding time. Consequently, sunflower was the preceding crop to wheat in both the years of study, whereas triticale was preceded by fallow in the 1998-1999 cropping season and wheat in the 1999-2000 cropping season (Table 1). Only wheat had the same preceding crop in both years and so was used to analyse the interaction between tillage and years. The combined effect of crop and preceding crop was determined in wheat and triticale following sunflower and wheat, respectively, in the season 1999/2000. These preceding crops have been reported to support different levels of AMF colonization, with sunflower being better colonized than wheat, i.e. more mycotrophic (Arihara \& Karasawa, 2000; Zhu et al., 2001). The choice of wheat and triticale as test crops was based on their being closely related small grain cereals, although triticale seems to be more mycotrophic than wheat (Cruz et al., 1998).

The soil was a Luvissol and the chemical characteristics of the $0-10 \mathrm{~cm}$ and $10-20 \mathrm{~cm}$ soil layers for the two tillage treatments are given in Table 2 for the two fields. Phosphorus and $\mathrm{K}$ were quantified by the Egner-Riehm method (Riehm, 1958), and organic matter was evaluated according to Anne

Table 1 Crop rotation of the experiment in the preceding year and the 2 yrs of study

\begin{tabular}{llll}
\hline Year & \multicolumn{3}{c}{ Crops in the rotation } \\
\hline $1997-1998$ & Sunflower & Fallow & Triticale \\
$1998-1999($ year 1) & Wheat & Triticale & Sunflower \\
$1999-2000$ (year 2) & Triticale & Sunflower & Wheat \\
\hline
\end{tabular}


Table 2 Some chemical characteristics of the soil ( $\mathrm{P}$ and $\mathrm{K}$ by Egnerr - Riehm method)

\begin{tabular}{|c|c|c|c|c|c|c|c|c|}
\hline \multirow{3}{*}{$\begin{array}{l}\text { Depth } \\
(\mathrm{cm})\end{array}$} & \multicolumn{2}{|c|}{$\begin{array}{c}\mathrm{P} \\
(\mathrm{mg} / \mathrm{kg})\end{array}$} & \multicolumn{2}{|c|}{$\begin{array}{c}\mathrm{K} \\
(\mathrm{mg} / \mathrm{kg})\end{array}$} & \multicolumn{2}{|c|}{$\begin{array}{c}\mathrm{pH} \\
(1: 2 \text { water })\end{array}$} & \multicolumn{2}{|c|}{$\begin{array}{c}\mathrm{OM} \\
(\mathrm{mg} / \mathrm{g})\end{array}$} \\
\hline & Year & Year & Year & Year & Year & Year & Year & Year \\
\hline & 1 & 2 & & & & & & \\
\hline \multicolumn{9}{|l|}{ No till } \\
\hline $0-10$ & 17 & 26 & 67 & 69 & 5.6 & 5.3 & 16 & 16 \\
\hline $10-20$ & 11 & 11 & 46 & 49 & 5.7 & 5.7 & 14 & 9 \\
\hline \multicolumn{9}{|c|}{ Conventional tillage } \\
\hline $0-10$ & 10 & 8 & 46 & 49 & 5.6 & 5.6 & 12 & 10 \\
\hline $10-20$ & 9 & 7 & 50 & 52 & 5.5 & 5.6 & 11 & 10 \\
\hline
\end{tabular}

(1945). Precipitation was under the long-term average during the autumn and winter in both years, but heavy rainfall events occurred in 99/2000 season, in April (flowering period for the cereals) and May, significantly exceeding the $30 \mathrm{yrs}$ average, whereas in the first season spring rainfall was close to the $30 \mathrm{yrs}$ mean (Figure 1). Such variability in weather pattern is typical of a Mediterranean climate. Overall, the temperature regime during the study was consistent with the 30 yrs average (Figure 2).

In both seasons, tillage was performed on the CT plots and glyphosate (540 $\mathrm{g}$ of active ingredient per ha) was applied on NT plots for weed control in the second week of November. Wheat and triticale were sown on both tillage treatments (CT and NT) in the second half of November, at a seed density of $190 \mathrm{~kg} / \mathrm{ha}$. A John Deere 'No-Till Drill' was used. Fertilizer (150 kg/ha of 18.12.0, NPK) was broadcasted at seeding for both crops and tillage treatments. In January of both seasons, post-emergence chemical weed control was performed with diclofop-methyl, (3 L/ha Illoxan by Bayer) and tribenuronmethyl (20 g/ha Granstar by Dupont). In February, crops received a second top dressing of $150 \mathrm{~kg} / \mathrm{ha}$ of $26 \%$

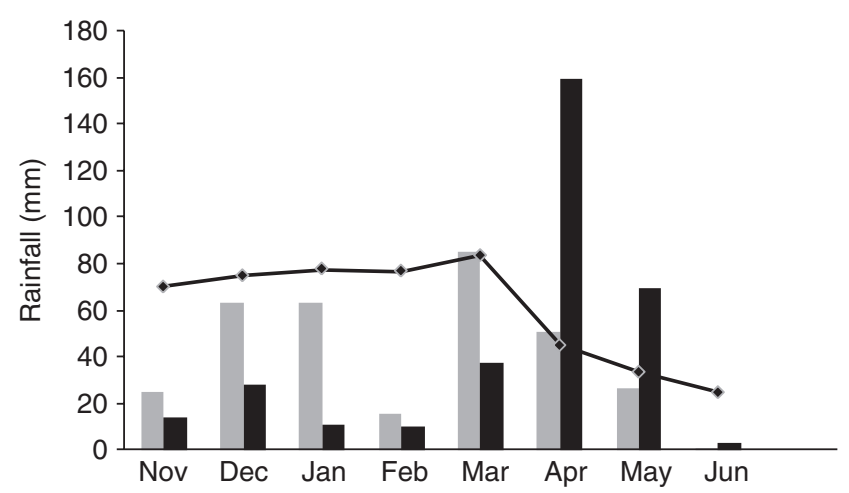

Figure 1 Rainfall distribution and 30-yrs average: grey bars- year 1, black bars - year 2, line - long-term average.

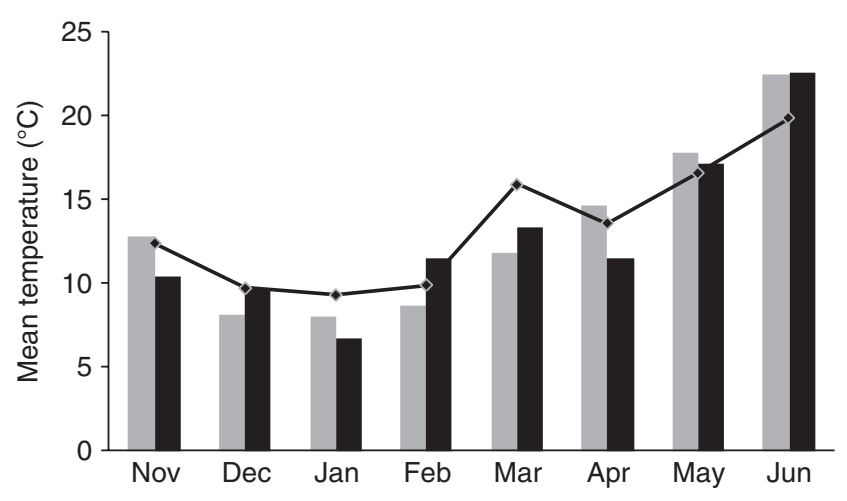

Figure 2 Mean monthly temperature $\left({ }^{\circ} \mathrm{C}\right)$ and 30 -yrs average: grey bars- year 1, black bars - year 2, line - long-term average.

ammonium-nitrate. The crops were harvested on the second week of July in both seasons.

To investigate the importance of the tillage system and crops as tools to manage AMF within the cropping system, the parameters measured focussed on spore numbers in the soil and AMF colonization rate in the crops. In both years, soil samples were randomly collected from the top $20 \mathrm{~cm}$ immediately before sowing the wheat, to quantify the effect of tillage on the number of AMF spores. In the second year, the triticale field was also sampled with the same procedure to evaluate the effect of the preceding crop and its interaction with tillage on AMF spores number. From each plot a composite sample was obtained by pooling three soil cores. Soil samples were passed through a $4 \mathrm{~mm}$ sieve before being air dried. Two sub-samples of air-dried soil from each plot were used for spore extraction according to Gerdemann \& Nicolson (1963). Only bright, apparently viable, spores were counted.

Root sampling for assessment of AMF colonization took place from March (stem elongation) through June (maturity) at ca. 2 week intervals. Roots from three randomly selected plants in each plot were sampled with a hand-operated soil probe $(5 \mathrm{~cm}$ diameter) to a depth of $20 \mathrm{~cm}$. This sampling procedure was consistent with that used by Mohammad et al. (1998) and Al-Karaki et al. (2004) to evaluate the seasonal variability of AMF colonization. Roots were stained with trypan blue and assessment of colonization was made by the grid line intersection method of Giovannetti \& Mosse (1980). In this work, we estimated colonization as a percentage of root length where the fungus was present.

As the preceding crop to triticale was not the same in both years of the experiment, four different ANOVA analyses were performed. To evaluate the interaction between years and tillage treatments only results from wheat fields were used with sunflower as the preceding crop in both years. To evaluate the effect of this interaction on AMF spore numbers, tillage was used as a factor combined over years. For AMF colonization of wheat, tillage and sampling date 
were used as factors, considering a split plot design with the latter as the second level factor combined over the 2 yrs. To evaluate the interactions between tillage and crops, only the second year of the experiment was used. For AMF spore numbers, tillage was combined over crops, because results were related to information from two fields, and for AMF colonization tillage and sampling date (on a split plot design) were also combined over crops. Results were analysed with MSTAT-C (version 1.42; Michigan State University) statistical package. Tukey's mean separation test was used whenever significant differences $(P \leq 0.05)$ were detected in the ANOVA.

\section{Results}

The ANOVA used to evaluate the interaction between years and tillage for the sampling dates within years showed significant effects of the main factors (years, tillage and sampling time) and the two-way interactions between each one of these factors. However, the three way interaction was not significant. A similar result was obtained when tillage, crops and sampling time were analysed, such that although there was a significant effect of the main factors and the twoway interaction between each pair was significant, the three way interaction was not significant.

There was a significant interaction between tillage and years in relation to AMF spore numbers (Figure 3). For NT spore numbers were $32 \%$ greater $(P<0.05)$ than those for $\mathrm{CT}$ in the first year, but in the second year, when the number of spores counted was far fewer, the difference, though similar in relative value, was not significant at $P=0.05$. Arbuscular mycorrhizal fungi spore numbers were not significantly affected by the interaction between tillage and the preceding crop.

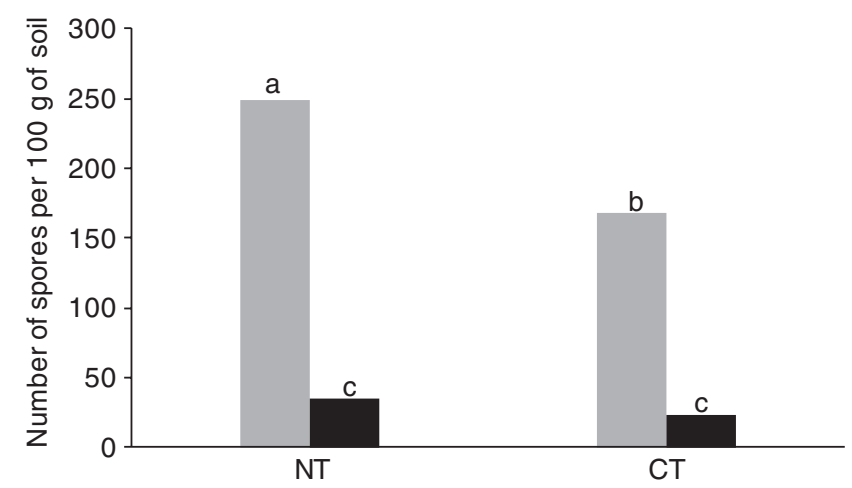

Figure 3 Effect of tillage system - No till (NT) or Conventional tillage $(\mathrm{CT})$ - on spore numbers from arbuscular mycorrhizal fungi over 2 yrs, prior to the seeding of wheat: grey bars - year 1; black bars - year 2. Letters indicate significant differences between treatments $(P=0.05)$.
The AMF colonization rate for wheat was significantly affected by the interactions between year and sampling date (Figure 4) and between tillage and sampling date (Figure 5), but not by the interactions between tillage and year (Table 3 colonization rate under NT was always greater than under CT) or between the three factors (results not presented). The significantly greater AMF colonization of wheat in the second year was related to the larger value observed at full flowering (Figure 4). The AMF colonization rate of the wheat under NT was consistently and significantly greater than under CT on each sampling occasion, although the differences were smaller towards the end of the sampling period (Figure 5).

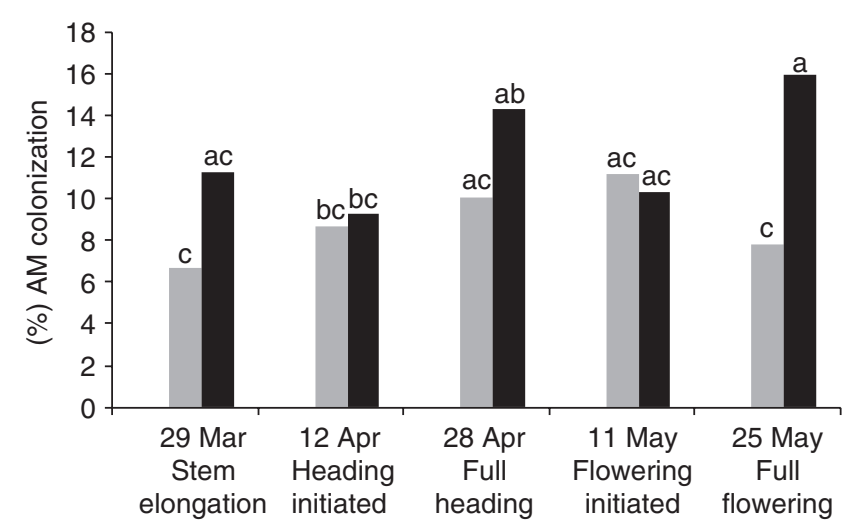

Figure 4 Variation in percentage of wheat root length colonized by arbuscular mycorrhiza (AM) with time over 2 yrs: grey bars - year 1, black bars - year 2. Letters indicate significant differences $(P=0.05)$ between years in $\mathrm{AM}$ colonization rates on specific sampling occasions.

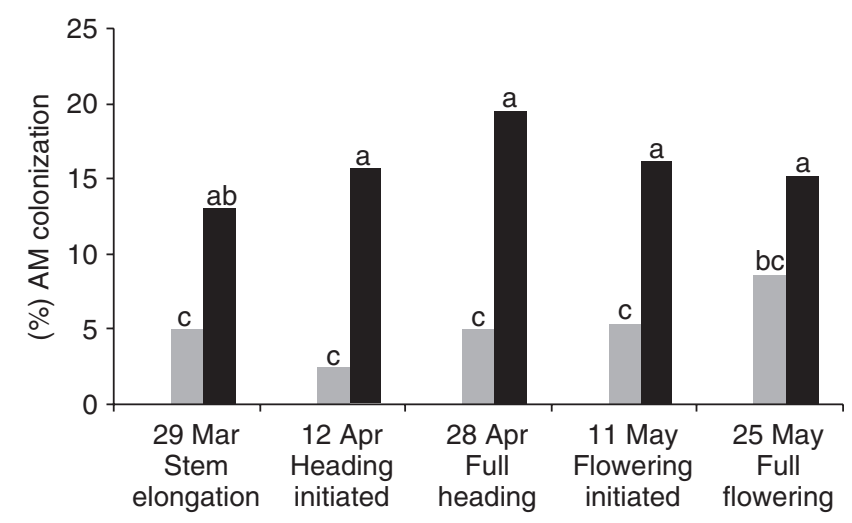

Figure 5 Effect of tillage system on the percentage of wheat root length colonized by arbuscular mycorrhiza (AM) with time. The results are the average values for years 1 and 2: grey bars Conventional tillage, black bars - No-till. Letters indicate significant differences $(P=0.05)$ between tillage systems in AM colonization rates on specific sampling occasions. 
Table 3 Effect of tillage system (no-till or conventional tillage) on $\%$ of AM colonization of wheat $(0-20 \mathrm{~cm})$ over 2 yrs

\begin{tabular}{lrrr}
\hline Tillage system & Year 1 & Year 2 & Mean \\
\hline No-till & $13 \mathrm{a}$ & $18 \mathrm{a}$ & $16 \mathrm{~A}$ \\
Conventional tillage & $4 \mathrm{~b}$ & $6 \mathrm{~b}$ & $5 \mathrm{~B}$ \\
Mean & $9 \mathrm{~B}$ & $12 \mathrm{~A}$ & \\
\hline
\end{tabular}

$\mathrm{AM}$, arbuscular mycorrhiza. Capital letters indicate significant differences $(P=0.05)$ between means of primary treatments. Small letters indicate significant differences $(P=0.05)$ between the interaction of the two factors.

Arbuscular mycorrhizal fungi colonization varied significantly between triticale and wheat with the former consistently showing larger values from stem elongation to the beginning of flowering (Figure 6). However, from full flowering to grain filling the opposite occurred, with AMF colonization of wheat being significantly larger (Figure 6).
For both crops, AMF colonization rates increased from the first assessment in March until the end of April, but declined thereafter.

The AMF colonization rate was strongly affected by the tillage system, with significantly greater colonization being associated with NT at all sampling dates (Figure 7) and for both crops overall (Figure 8). The significant interaction between tillage and sampling date resulted from the differences between the two tillage systems being smaller, but still significant, at the beginning (stem elongation) and at the end of the crop cycle (grain filling) (Figure 7).

The effect of tillage on AMF colonization was larger than that of the combined effect of the crop and the preceding crop (wheat after sunflower and triticale after wheat). Over all sampling dates, AMF colonization rate in triticale was $39 \%$ greater than in wheat, whereas for tillage, colonization under NT was $154 \%$ greater than in CT (Figure 8). We found no significant interaction between crop and tillage system.
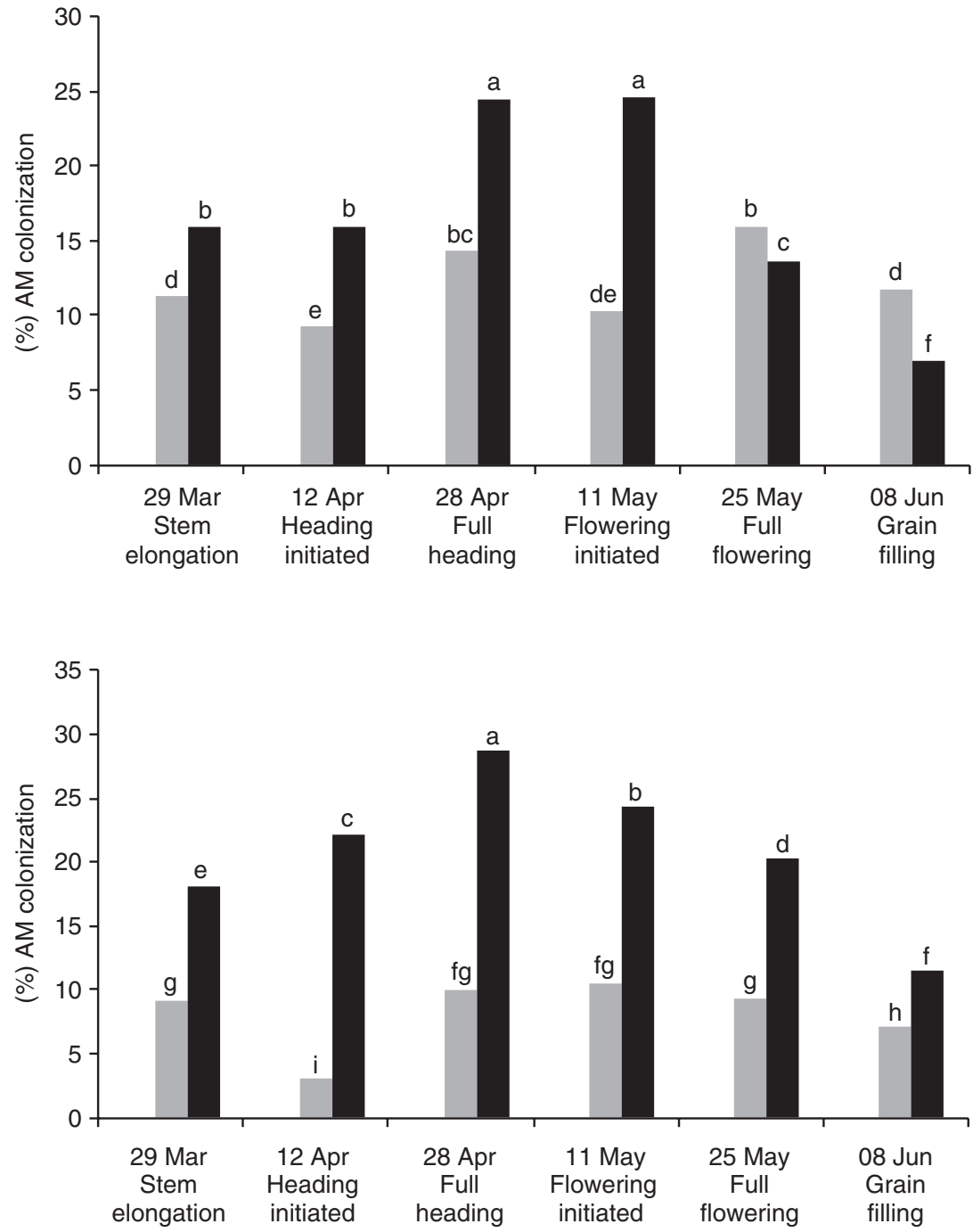

Figure 6 The difference between the percentage root length of wheat and triticale colonized by arbuscular mycorrhiza (AM) over time in year 2. Results are the means for the two tillage systems: grey bars - wheat, black bars - triticale. Letters indicate significant differences $(P=0.05)$ between crops in AM colonization rates on specific sampling occasions.
Figure 7 Effect of tillage system on percentage of root length colonized by arbuscular mycorrhiza (AM) with time in year 2 . The results are the average values for wheat and triticale: grey bars Conventional tillage, black bars - No-till. Letters indicate significant differences $(P=0.05)$ between tillage systems in AM colonization rates on specific sampling occasions. 


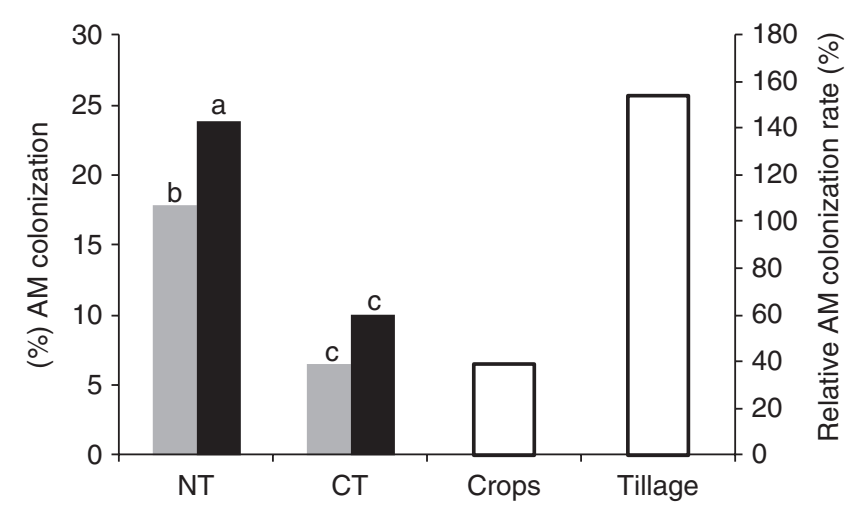

Figure 8 Effect of tillage system [No till (NT) or Conventional tillage (CT)] and crop [wheat (grey bars) or triticale (black bars)] on the percentage of root length colonized by arbuscular mycorrhiza in year 2 - left axis. The relative increases of triticale over wheat (Crops) and NT over CT (Tillage) are also shown - right axis. Letters indicate significant differences between treatments $(P=0.05)$.

\section{Discussion}

The number of AMF spores found in the soil was not significantly affected by the preceding crop under the typical Mediterranean conditions. The number of spores in the soil between the sunflower and wheat crops was similar to that found in soil between the wheat and triticale crops. This was unexpected because sunflower is considered a highly mycotrophic crop and grows over the summer (Arihara \& Karasawa, 2000). The effect of tillage on spore number just before seeding was dependent on the year and this could have been due to the possible confounding effect of the wheat field location in this study. The increase in spore number present under NT is consistent with the results found by Kabir et al. (1998a).

Despite fewer AMF spores being found in the soil in year 2 than in year 1, wheat AM colonization was significantly greater in the second year, consistent with the view that other sources of inoculum were more important than spores.

Arbuscular mycorrhizal fungi colonization of triticale was significantly greater than in wheat until the beginning of the reproductive stage. Cruz et al. (1998) also found that triticale was a more mycotrophic crop than wheat. During flowering and grain filling stage, AM colonization decreased in both crops. Similar patterns were described by Mohammad et al. (1998) and Al-Karaki et al. (2004). The decline is probably associated with the development of the new major sink in the grain, with the result that roots then received less carbohydrate (Cade-Menun et al., 1991). The different behaviour of the two crops on the two last sampling occasions could have been due to the shorter period of maturation observed for triticale.

Our results clearly indicate that tillage influenced AMF colonization throughout the entire cycle of both crops in contrast to the combined effects of the crop and the preceding crop. Arbuscular mycorrhizal fungi colonization under NT was significantly greater than under CT in both years even though the number of spores in the soil could have affected this result only in the first year. This was also consistent with the suggestion that other forms of inoculum were more important than spores, with NT being less destructive of these forms compared with CT. The disruption of the extraradical mycelia network during CT, as described by Evans \& Miller (1990), was the likely cause of the smaller AMF colonization in this treatment. It is notable that whereas the level of colonization remained more or less constant under CT, it tended to follow a quadratic pattern under NT. The results are consistent with the summer survival of extraradical mycelium under Mediterranean conditions (Brito et al., 2011), specially when the soil is not disturbed (Jasper et al., 1989). The greater AM colonization of plants cultivated under NT than CT has also been reported by other authors (e.g. Evans \& Miller, 1988; Kabir et al., 1998b). Differences between tillage systems were still evident at the end of the sampling period, probably because the effect of tillage was greater than the combined effects of the crop and previous crop.

\section{Conclusions}

Our results confirm that the preceding crop influences AMF colonization of the next crop by the extraradical mycelium developed and the number of spores produced. Under CT, disruption of the extraradical mycelium leaves spores as the main source of AMF inoculum for the next crop. However, under the Mediterranean conditions in our study spore number was not consistently reduced by tillage and was unaffected by cropping sequence. Once the benefits of NT extend beyond the effect of the crop species and season due to the preservation of the extraradical mycelium, it seems to be a more powerful tool, than does preceding crop, to manage AMF colonization within a mycotrophic cropping system under Mediterranean conditions.

\section{References}

Abbott, L.K. \& Robson, A.D. 1991. Field management of VA mycorrhizal fungi. In: The rhizosphere and plant growth (eds D.L. Keister \& P.B. Cregan), pp. 355-362. Kluwer Academic Publishers, Dordrecht, Netherlands.

Al-Karaki, G.N., McMichael, B. \& Zak, J. 2004. Field response of wheat to arbuscular mycorrhizal fungi and drought stress. Mycorrhiza, 14, 263-269.

Anne, P. 1945. Sur le dosage rapide du carbone organique des sols. Annales Agronomiques, 15, 161-172.

Arihara, J. \& Karasawa, T. 2000. Effect of previous crops on arbuscular mycorrhizal formation and growth of succeeding maize. Soil Science and Plant Nutrition, 46, 43-51. 
Black, R.L.B. \& Tinker, P.B. 1977. Interaction between effects of vesicular-arbuscular mycorrhiza and fertilizer phosphorus on yields of potatoes in the field. Nature, 267, 510-511.

Brito, I., Carvalho, M. \& Goss, M.J. 2011. Summer survival of arbuscular mycorrhiza extraradical mycelium and the potential for its management through tillage options in Mediterranean cropping systems. Soil Use and Management, 27, 350-356.

Cade-Menun, B.J., Berch, S.M. \& Bomke, A.A. 1991. Seasonal colonization of winter wheat in south coastal British Columbia by VAM fungi. Canadian Journal of Botany, 69, 78-86.

Cruz, I.P., Gayosso, E.M., Cruz-Flores, G., Monasterio, I.O. \& Manske, G.G.B. 1998. Colonizacion micorrizica arbuscular, actividad fosfatasica y longitud radical como respuesta a estres de fosforo en trigo y triticale cultivados en un andisol. Terra, 16, 55-61.

Evans, D.G. \& Miller, M.H. 1988. Vesicular-arbuscular mycorrhizas and the soil-disturbance-induced reduction of nutrient absorption in maize. I. Causal relations. New Phytologist, 110, 67-74.

Evans, D.G. \& Miller, M.H. 1990. The role of the external mycelial network in the effect of soil disturbance upon vesicular-arbuscular mycorrhizal colonization of maize. New Phytologist, 114, 65-71.

Friese, C.F. \& Allen, M.F. 1991. The spread of VA mycorrhizal fungal hyphae in the soil: inoculum types and external hyphal architecture. Mycologia, 83, 409-480.

Gavito, M.E. \& Miller, M.H. 1998. Changes in mycorrhiza development in maize induced by crop management practices. Plant and Soil, 198, 185-192.

Gerdemann, J.W. \& Nicolson, T.H. 1963. Spore of mycorrhizal Endogone species extracted from soil by wet sieving and decanting. Transactions of the British Mycological Society, 80, $552-557$.

Giovannetti, M. \& Mosse, B. 1980. An evaluation of techniques for measuring vesicular arbuscular mycorrhizal infection in roots. New Phytologist, 84, 489-500.

Goss, M.J. \& de Varennes, A. 2002. Soil disturbance reduces the efficacy of mycorrhizal associations for early soybean growth and N2 fixation. Soil Biology and Biochemistry, 34, 1167-1173.

Graham, J.H. \& Abbott, L.K. 2000. Wheat responses to aggressive and non-aggressive arbuscular mycorrhizal fungi. Plant and Soil, 220, 207-218.

Gupta, V., Satyanarayana, T. \& Garg, S. 2000. General aspects of mycorrhiza. In: Mycorrhizal biology (eds K.G. Mukherji, B.P. Chamola \& J. Singh), pp. 27-44. Kluwer Academic/Planum Publ, Dordrecht, Netherlands.

Jasper, D.A., Abbott, L.K. \& Robson, A.D. 1989. Hyphae of a vesicular-arbuscular mycorrhizal fungus maintain infectivity in dry soil, except when the soil is disturbed. New Phytologist, 112, 101-107.

Johnson, N.C., Graham, J.H. \& Smith, F.A. 1997. Functioning of mycorrhizal associations along the mutualism-parasitism continuum. New Phytologist, 135, 575-586.

Kabir, Z. 2005. Tillage or no-tillage: impact on mycorrhizae. Canadian Journal of Plant Science, 85, 23-29.

Kabir, Z., O’Halloran, I.P., Fyles, J.W. \& Hamel, C. 1998a. Dynamics of the mycorrhizal symbiosis of corn (Zea mays L.): effects of host physiology, tillage practice and fertilization on spatial distribution of extra-radical mycorrhizal hyphae in the field. Agriculture, Ecosystems and Environment, 68, 151-163.

Kabir, Z., O'Halloran, I.P., Widden, P. \& Hamel, C. 1998b. Vertical distribution of arbuscular mycorrhizal fungi under corn (Zea mays L.) in no-till and conventional tillage systems. Mycorrhiza, 8, 53-55.

Karasawa, T., Arihara, J. \& Kasahara, Y. 2000. Effects of previous crops on arbuscular mycorrhizal formation and growth of maize under various soil moisture conditions. Soil Science and Plant Nutrition, 46, 53-60.

Klironomos, J.N. \& Hart, M.M. 2002. Colonization of roots by arbuscular mycorrhizal fungi using different sources of inoculum. Mycorrhiza, 12, 181-184.

Martin-Rueda, I., Muñoz-Guerra, L.M., Yunta, F., Esteban, E., Tenório, J.L. \& Lucena, J.J. 2007. Tillage and crop rotation effects on Barley yield and soil nutrients on a Calciortidic Haploxeralf. Soil and Tillage Research, 92, 1-9.

Martins, M.A. \& Read, D.J. 1997. The effects of disturbance on the external mycelium of arbuscular mycorrhizal fungi on plant growth. Pesquisa Agropecuária Brasileira, 32, 1183-1189.

McGonigle, T.P. \& Miller, M.H. 2000. The inconsistent effect of soil disturbance on colonization of roots by arbuscular mycorrhizal fungi a test of the inoculum density hypothesis. Applied Soil Ecology, 14, 147-155.

Miller, M.H. 2000. Arbuscular mycorrhizal and the phosphorus nutrition of maize: a review of Guelph studies. Canadian Journal of Plant Science, 80, 47-52.

Mohammad, M.J., Pan, W.L. \& Kennedy, A.C. 1998. Seasonal mycorrhizal colonization of winter wheat and its effect on wheat growth under dryland field conditions. Mycorrhiza, 8, 139-144.

Read, D.J., Koveheri, H.K. \& Hodson, J. 1976. Vesicular-arbuscular mycorrhiza in natural vegetation systems. New Phytologist, 77, 641-653.

Riehm, H. 1958. Die ammoniumlaktatessigsaure-Method zur bestimmung der leichtloslichen phosphorsaure in karbonathaltigen boden. Agrochimica, 3, 49-65.

Schwartz, M.W., Hoeksema, J.D., Gehring, C.A., Johnson, N.C., Klironomos, J.N., Abbott, L.K. \& Pringle, A. 2006. The promise and the potential consequences of the global transport of mycorrhizal fungal inoculum. Ecology Letters, 9, 501-515.

Smith, S.E. \& Read, D.J. 1997. Mycorrhizal symbiosis. Academic Press, London.

Triplett, G.B. Jr \& Van Doren, D.M. Jr 1969. Nitrogen, phosphorus, and potassium fertilization of non-tilled maize. Agronomy Journal, 61, 637-639.

Troeh, Z.I. \& Loynachan, T.E. 2003. Endomycorrhizal fungal survival in continuous corn, soybean, and fallow. Agronomy Journal, 95, 224-230.

Vestberg, M., Saari, K., Kukkonen, S. \& Hurme, T. 2005. Mycotrophy of crops in rotation and soil amendment with peat influence the abundance and effectiveness of indigenous arbuscular mycorrhizal fungi in field soil. Mycorrhiza, 15, 447-458.

Zhu, Y.G., Smith, S.E., Barritt, A.R. \& Smith, F.A. 2001. Phosphorus (P) efficiencies and mycorrhizal responsiveness of historical and modern wheat cultivars. Plant and Soil, 237, 249-255. 